\title{
Is laryngeal hypersensitivity the basis of unexplained or refractory chronic cough?
}

\author{
Krishna M. Sundar (10 ${ }^{1,6}$, Amanda Carole Stark ${ }^{2,6}, \mathrm{Nan} \mathrm{Hu}^{3}$ and \\ Julie Barkmeier-Kraemer (1) ${ }^{4,5}$
}

Affiliations: ${ }^{1}$ Dept of Internal Medicine, University of Utah, Salt Lake City, UT, USA. ${ }^{2}$ National Center for Voice and Speech, University of Utah, Salt Lake City, UT, USA. ${ }^{3}$ Dept of Biostatistics, Robert Stempel College of Public Health and Social Work and Division of Public Health, Florida International University, Miami, FL, USA. ${ }^{4}$ Division of Otolaryngology, University of Utah, Salt Lake City, UT, USA. ${ }^{5}$ Dept of Communication Sciences and Disorders, University of Utah, Salt Lake City, UT, USA. ${ }^{6}$ These authors contributed equally.

Correspondence: Krishna M. Sundar, Dept of Medicine, University of Utah, 375, Chipeta Way, Salt Lake City, UT 84108, USA. E-mail: krishna.sundarahsc.utah.edu

ABSTRACT Refractory chronic cough (RCC) and unexplained chronic cough (UCC) are common problems seen in primary care and subspecialty clinics. The role of cough hypersensitivity and laryngeal dysfunction in contributing to the persistence of cough in RCC/UCC is not well recognised.

Data of patients with RCC and UCC evaluated in 2019 by an interdisciplinary cough clinic led by a pulmonologist and speech-language pathology team was reviewed. Patients completed validated questionnaires including the Leicester cough questionnaire (LCQ), voice handicap index (VHI) and dyspnoea index (DI) questionnaire at initial encounter. Presence of cough hypersensitivity was based upon a history of allotussia and hypertussia. Laryngeal dysfunction was diagnosed in those with a history of laryngeal paresthesias, throat clearing, voice abnormalities, upper airway dyspnoea and documentation of functional or anatomic laryngeal abnormalities on nasoendoscopy.

Of the $60 \mathrm{UCC} / \mathrm{RCC}$ patients analysed, $75 \%$ of patients were female and $85 \%$ were over 40 years of age. Cough hypersensitivity was documented in all patients and multiple cough triggers occurred in $75 \%$ of patients. $95 \%, 50 \%$ and $25 \%$ of patients reported laryngeal paresthesias, voice abnormalities and upper airway dyspnoea, respectively. Significant associations between LCQ and VHI and DI scores occurred when adjusting for age, sex, ethnicity and body mass index. Laryngeal functional abnormalities were documented on 44 out of 60 patients on nasoendoscopy.

Hypertussia, allotussia and laryngeal dysfunction are common in patients with RCC and UCC. Evaluation of UCC and RCC can delineate laryngeal hypersensitivity and allows appropriate treatment to be directed at this phenotype.

@ERSpublications

Chronic refractory cough is frequently characterised by cough hypersensitivity and laryngeal dysfunction. An interdisciplinary team approach that includes laryngeal evaluation can identify laryngeal hypersensitivity along with other cough aetiologies. https://bit.ly/2XGi4Uk

Cite this article as: Sundar $\mathrm{KM}$, Stark $\mathrm{AC}, \mathrm{Hu} \mathrm{N}$, et al. Is laryngeal hypersensitivity the basis of unexplained or refractory chronic cough? ERJ Open Res 2021; 7: 00793-2020 [https://doi.org/10.1183/ 23120541.00793-2020].

( T) The authors 2021. This version is distributed under the terms of the Creative Commons Attribution Non-Commercial Licence 4.0. For commercial reproduction rights and permissions contact permissions@ersnet.org 


\section{Introduction}

Chronic cough is one of the most common clinical problems encountered in primary care and subspecialty clinics [1]. In the majority of patients, the underlying aetiology is thought to be gastro-oesophageal reflux disease (GORD), rhinosinusitis or cough variant asthma (CVA) when an empiric diagnostic approach to evaluate chronic cough is used [2]. While this approach to chronic cough attempts to link specific causal aetiologies to the occurrence of cough, a substantial proportion of patients persist with their cough despite conventional treatment(s) for these conditions [3]. Terminology, such as unexplained chronic cough (UCC), refractory chronic cough (RCC) and idiopathic cough highlight the diagnostic and therapeutic problems in $5-42 \%$ of chronic cough patients [3].

To understand the persistence of cough in such individuals, the phenomenon of cough hypersensitivity has been proposed [4]. Cough hypersensitivity is characterised by decreased cough thresholds to noxious and non-noxious stimuli [5]. In addition to abnormal triggering of cough, abnormalities in laryngeal sensation and function are frequently reported in patients with UCC and RCC [6].

This study tested the hypothesis that symptoms suggestive of laryngeal dysfunction and cough hypersensitivity underlie the clinical symptomatology of UCC/RCC. To test this hypothesis, patient data from an interdisciplinary team-based evaluation of UCC/RCC patients was analysed. The specific aims of this study included determination of the following. 1) Frequency of cough hypersensitivity symptoms documented during an initial clinical encounter in those diagnosed with RCC or UCC; 2) frequency of coexisting voice, breathing or swallowing abnormalities in those with RCC or UCC using validated questionnaires; and 3) frequency of laryngeal dysfunction documented during nasoendoscopy examination in those with RCC or UCC.

\section{Methods}

\section{Study design, setting and patients}

This was a one-year cohort study conducted according to the STROBE (Strengthening the Reporting of Observational Studies in Epidemiology) statement on recommendations for observational studies [7]. Patients were identified for inclusion in this study based on an electronic medical record review of all individuals seen in the interdisciplinary Cough Clinic at the University of Utah Voice Disorders Center from January 1, 2019, to December 31, 2019. Individuals with chronic cough are referred to this clinic from primary care providers, gastroenterologists, pulmonologists, allergists and otolaryngologists within the University of Utah Health system, or from local or regional locations. Candidates for this study were excluded if they were smokers or diagnosed with the following: a) chronic lung disease; b) congestive heart failure; c) neurological conditions including Parkinson's disease or stroke; d) head and neck cancer; or e) underwent prior laryngeal surgery. All patients included had normal chest radiology and pulmonary function tests (PFTs) or had abnormalities that did not contribute to the occurrence of chronic cough as determined by the team pulmonologist.

\section{Data sources}

All patients were evaluated by an interdisciplinary team that included a pulmonologist (K.M. Sundar) and speech-language pathology (SLP) team members clinically specialised in voice, cough/airway and swallowing disorders. Abnormal nasoendoscopy findings were reviewed by a laryngologist during a weekly multidisciplinary voice panel. Prior to the initial visit at the cough clinic, patients completed validated quality of life self-report questionnaires. These included: 1) Leicester Cough Questionnaire (LCQ) [8]; 2) voice handicap index (VHI) [9]; 3) dyspnoea index (DI) [10]; and 4) cough visual analogue scale score (VAS).

Instrumental voice and airway assessment was done per the American Speech Language and Hearing Association (ASHA) recommended protocol [11]. Data extracted from electronic medical records included patient demographics, cough characteristics, treatments rendered, speech assessment results and nasoendoscopic imaging findings.

\section{Variables measured \\ Cough hypersensitivity}

In this study, the presence of cough hypersensitivity was defined by the report of coughing in response to stimuli that typically do not lead to cough (allotussia), and exaggerated coughing in response to typical stimuli that elicit cough at lower doses (hypertussia) [12]. Thus, all reported triggers of coughing such as strong smells/perfumes, changes in body position, eating, temperature change, exercise, talking, etc. were included in the analysis. 


\section{Laryngeal dysfunction}

Categorisation of symptoms and signs of laryngeal dysfunction was done as follows. 1) Laryngeal paresthesias: report of globus sensation, a tickle or irritation in the throat; 2) Presence or absence of throat clearing; 3) laryngeal sensorimotor abnormality as indicated by self-reported symptoms of dysphonia, upper airway dyspnoea, and dysphagia indicating impaired laryngeal function (e.g. aspiration, or frequent occurrence of coughing relative to swallowing); and 4) anatomic or physiologic laryngeal abnormalities, based on nasoendoscopic examination reported by the treating SLP and confirmed by a laryngologist when a structural or neurological abnormality of the larynx was present.

\section{Outcomes from therapies rendered}

This study did not aim to assess outcomes from therapies rendered since objective outcome measures (e.g.VAS or LCQ total score) were not consistently available during follow-up visits across patients in this study. Patients were commonly treated with behavioural speech therapy (BST) based upon defined treatment protocols [13]. Patients also underwent screening and evaluation for obstructive sleep apnoea (OSA) that was based upon existing guidelines [14]. Patient outcomes following treatment were determined based upon subjective reports of improvement during follow-up visits or phone calls.

\section{Statistical analyses}

Data were summarised as mean \pm SD for continuous variables, and frequency (n) and percentage (\%) for categorical variables. Univariate linear regression was used to examine the association between continuous outcomes (LCQ, VAS, VHI, DI and number of triggers) and single-predictor variables (laryngeal paresthesia and throat clearing). Univariate logistic regressions were performed to associate the binary outcomes (laryngeal paresthesia, throat clearing and cough triggers) with LCQ, VHI and DI as the predictors and odds ratios were reported. Multivariate linear regression and logistic regression models were performed that adjusted for age, sex, BMI and ethnicity.

Analyses were performed using statistical software Stata (StataCorp., College Station, TX, USA) V.15. All tests were two-sided, and a p-value $<0.05$ indicates statistically significant results.

\section{Results}

\section{Patient characteristics}

85 patients with chronic cough were seen at the University of Utah interdisciplinary Cough Clinic during the study timeline. Of these, 25 were excluded from further analysis due to comorbidities or other exclusion criteria (figure 1). Mild restriction on PFTs was seen in four out of 60 patients, and three out of 60 had radiologic abnormalities (lung nodules in two and small cysts in one) that were not felt to contribute to the chronic cough and therefore, these patients were included in the final data analysis.

\section{Cough characteristics}

Table 1 outlines patient demographics and concomitant diagnoses related to their chronic cough. Nearly $75 \%$ of patients were female, with $85 \%$ of individuals above 40 years of age. Patients aged above 70 years comprised one-third of patients in the study and had the longest durations of cough (tables 1 and 2). 40\% of patients were obese $\left(\mathrm{BMI}>30 \mathrm{~kg} \cdot \mathrm{m}^{-2}\right.$ ) and less than one-third of patients (17 out of 60) had normal BMI of $\leqslant 25 \mathrm{~kg} \cdot \mathrm{m}^{-2}$ with the rest of subjects in the overweight category. Cough duration of $\geqslant 10$ years was reported in 10 out of 60 patients, but cough duration was not significantly associated with patients' age as a continuous variable $(\mathrm{p}=0.068$ ). Mean duration of cough was not significantly longer in men than women (87.1 months versus 71.5 months; $\mathrm{p}=0.61$ ). Cough was rated as moderate to severe based on VAS scores $(63.79 \pm 0.47 \mathrm{~mm})$ and total LCQ scores $(9.91 \pm 2.75)$. Cough duration was not predictive of total LCQ or VAS scores $(\mathrm{p}=0.609$ and 0.069 , respectively). Paroxysms of cough were reported by the majority of patients, although more frequently in those less than 70 years of age. There was no effect of age, sex, BMI, cough duration and LCQ on the occurrence of paroxysms of cough.

Of the one-third of patients (20 out of 60) experiencing cough onset with a presumed respiratory tract infection (RTI), females reported an RTI more frequently than men (OR 1.71, 95\% CI 0.47-6.21); however, this difference was not significantly different $(p=0.412)$. Another one-sixth of patients reported events, such as exposure to strong chemicals, acute pulmonary conditions (such as pulmonary embolism), periods of excessive voice use and life stressors at the onset of chronic cough.

Even though the majority of patients reported previous active treatments for GORD, CVA and rhinosinusitis, only cough aetiologies ascertained at the time of initial clinic visit were included in table 1. At the time of initial evaluation, $75 \%$ of patients did not have symptoms to suggest one or more of the three aetiologies of GORD, UACS and rhinosinusitis. Only 15 out of 60 patients reported one or more of these three disorders to be an ongoing problem contributing to cough. Particularly for GORD, 42 out of 


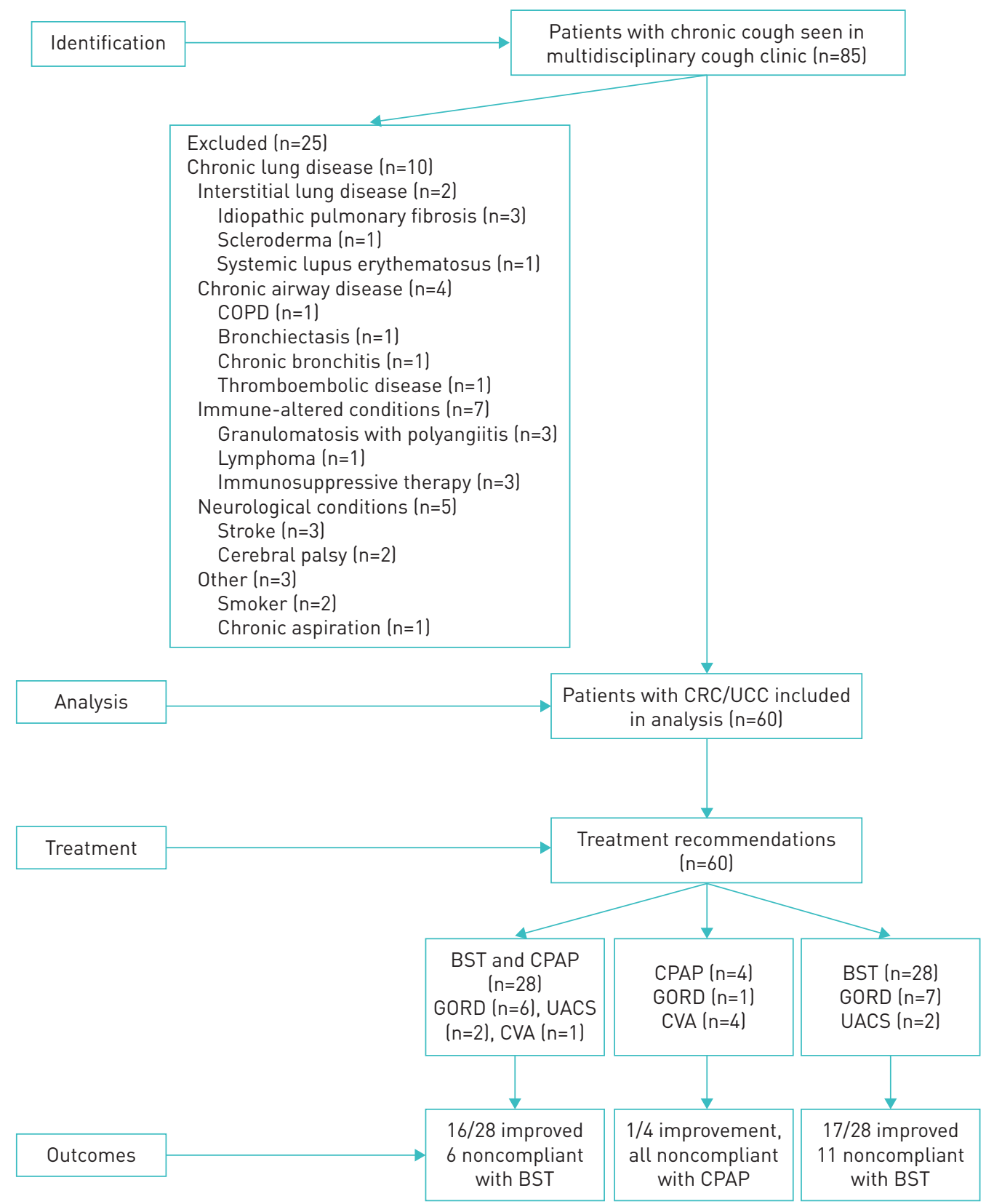

FIGURE 1 Flow diagram of patients screened and enrolled into observational cohort of patients with chronic refractory cough (CRC) and unexplained chronic cough (UCC). COPD: chronic obstructive pulmonary disease; GORD: gastro-oesophageal reflux disease; UACS: upper airway cough syndrome; CVA: cough variant asthma; BST: behavioural speech therapy; CPAP: continuous positive airway pressure.

60 patients were previously treated or were on treatment with anti-acid therapies (proton-pump inhibitors and/or histamine-2 receptor blockers) for months to years without improvement in cough.

\section{Cough hypersensitivity}

Cough hypersensitivity was determined based on symptoms of allotussia and hypertussia. Cough triggers ranged from talking to strong perfumes with talking being the most common trigger for cough (figure 2). The amount of talking required to trigger cough varied between patients and was not quantified within clinical records. Patients experiencing coughing from multiple triggers were noted in $75 \%$ (45 out of 60 ) of patients. No significant relationships occurred between the number of cough triggers and LCQ scores, presence of laryngeal paresthesia, frequent throat clearing, VHI or DI scores. 
TABLE 1 Demographics of patients and cormorbidities diagnosed

\begin{tabular}{|c|c|c|c|c|c|c|}
\hline & \multirow[t]{2}{*}{ Overall } & \multicolumn{3}{|c|}{ Age-distribution } & \multicolumn{2}{|c|}{ Sex-distribution } \\
\hline & & $18-40$ years & $41-70$ years & $>70$ years & Male & Female \\
\hline Patients n & 60 & 9 & 33 & 18 & 16 & 44 \\
\hline Age years & $59.5 \pm 16.4$ & $30.53 \pm 7.9$ & $58.50 \pm 8.8$ & $76.08 \pm 4.3$ & $55.06 \pm 16.2$ & $61.22 \pm 16.3$ \\
\hline \multicolumn{7}{|l|}{ Sex } \\
\hline Male & 16 & 2 & 10 & 4 & & \\
\hline Female & 44 & 7 & 23 & 14 & & \\
\hline$B M I \mathbf{k g} \cdot \mathrm{m}^{-2}$ & $29.47 \pm 6.4$ & $28.87 \pm 7.13$ & $30.11 \pm 6.7$ & $28.65 \pm 5.8$ & $30.49 \pm 3.8$ & $29.07 \pm 7.2$ \\
\hline \multicolumn{7}{|l|}{ Race/ethnicity } \\
\hline White & 52 & 5 & 29 & 18 & 15 & 37 \\
\hline Hispanic & 2 & 1 & 1 & 0 & 0 & 2 \\
\hline Asian & 2 & 1 & 1 & 0 & 1 & 1 \\
\hline Pacific Islander & 1 & 1 & 0 & 0 & 0 & 1 \\
\hline African American & 1 & 0 & 1 & 0 & 0 & 1 \\
\hline Other & 4 & 2 & 2 & 0 & 0 & 4 \\
\hline \multicolumn{7}{|l|}{ Comorbidities } \\
\hline GORD & 9 & 0 & 7 & 2 & 2 & 7 \\
\hline UACS & 2 & 0 & 2 & 0 & 1 & 2 \\
\hline CVA & 1 & 0 & 0 & 1 & 0 & 0 \\
\hline GORD and UACS & 2 & 0 & 0 & 2 & 2 & 0 \\
\hline None & 46 & 9 & 24 & 13 & 11 & 35 \\
\hline
\end{tabular}

Data are presented as $n$ or mean \pm SD. GORD: gastro-oesophageal reflux disease; UACS: upper airway cough syndrome; CVA: cough variant asthma.

\section{Laryngeal dysfunction}

The majority of individuals reported abnormal laryngeal sensations (57 out of 60 ) described as tickle, globus (lump or sensation in the throat), irritation, dry throat, sore throat and presence of mucus in the throat. Multiple different descriptors were noted in 10 out of 60 patients. Women reported a higher prevalence of abnormal throat sensations that were associated with increasing age. Nearly half of the patients reported frequent throat clearing. Presence of throat clearing was not related to LCQ or other signs or symptoms of laryngeal dysfunction.

Voice abnormalities were reported in more than half the patients that included hoarseness, loss of voice with talking or singing, change in pitch or a raspy voice quality. One-quarter of patients reported symptoms of upper airway dyspnoea, such as throat constriction and difficulty getting in air when dyspnoeic. Using the DI score index, 75\% of patients reported abnormal scores and VHI total scores were abnormal in $43 \%$ of patients. A significant unadjusted association (when not adjusting for age, sex and

\section{TABLE 2 Cough characteristics of patients}

\begin{tabular}{|c|c|c|c|c|c|c|}
\hline & Overall & \multicolumn{3}{|c|}{ Age-distribution } & \multicolumn{2}{|c|}{ Sex-distribution } \\
\hline Patients n & 60 & 9 & 33 & 18 & 16 & 44 \\
\hline \multicolumn{7}{|l|}{ LCQ } \\
\hline Mean \pm SD & $9.91 \pm 2.75$ & $9.56 \pm 2.6$ & $10.08 \pm 2.699$ & $9.77 \pm 3.027$ & $8.89 \pm 1.89$ & $10.25 \pm 2.9$ \\
\hline $\mathrm{n}$ & 56 & 9 & 31 & 16 & 16 & 42 \\
\hline $\mathrm{n}$ & 56 & 8 & 31 & 56 & 16 & 40 \\
\hline \multicolumn{7}{|c|}{ Paroxysms of coughing } \\
\hline Present & 44 & 7 & 27 & 10 & 11 & 33 \\
\hline Absent & 8 & 2 & 3 & 3 & 1 & 7 \\
\hline Not reported & 8 & 0 & 3 & 5 & 4 & 4 \\
\hline
\end{tabular}



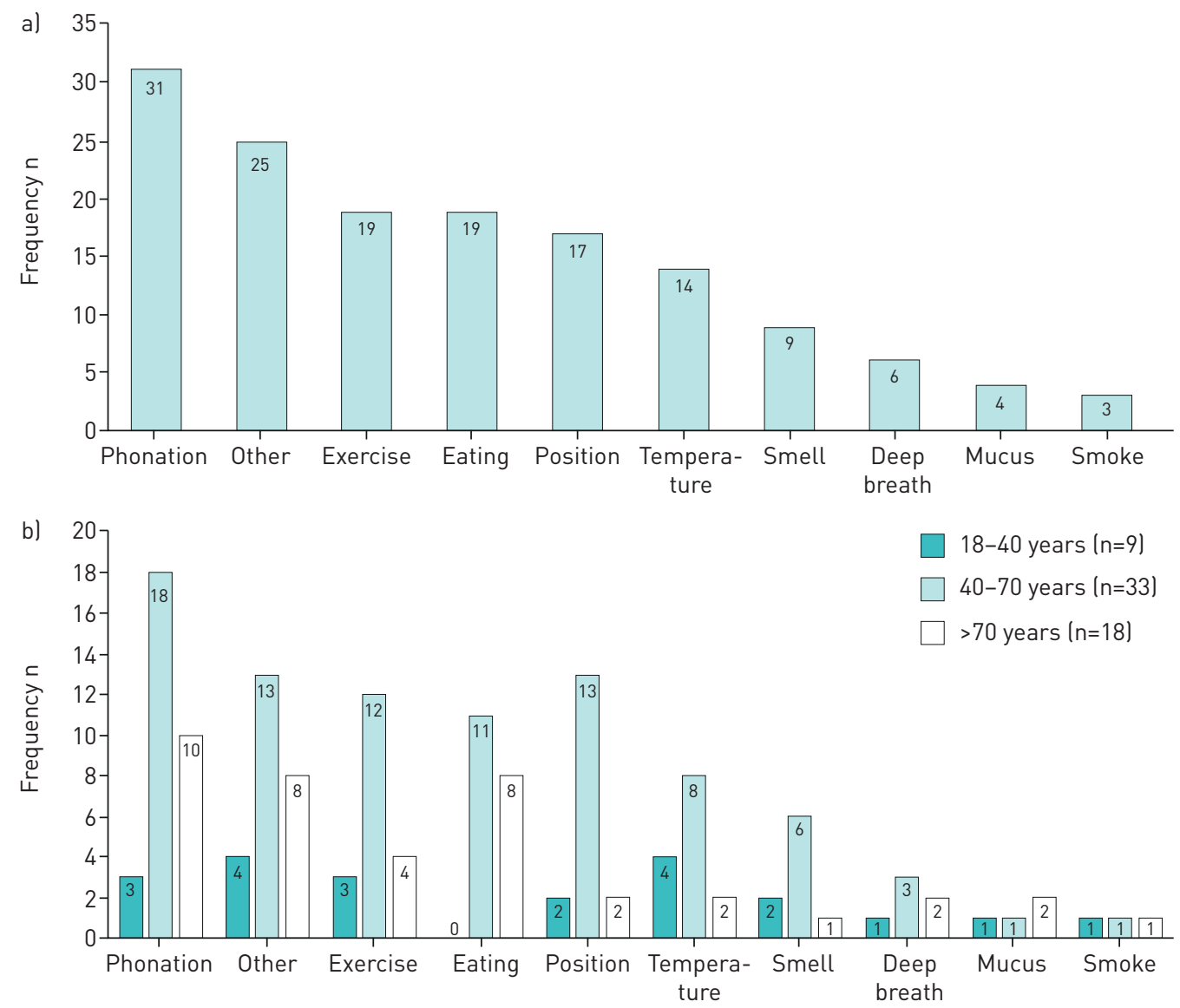

FIGURE 2 Frequency of cough-related triggers, overall (a) and based upon different age groups (b). n: number of patients.

BMI) was shown between total scores on the LCQ and VAS, and between VHI and DI scores. Higher VHI total scores were associated with worse (i.e. lower) LCQ scores (coefficient=-3.4 change in LCQ) when adjusting for age, sex, ethnicity and BMI $\left(\mathrm{p}=0.001, \mathrm{R}^{2}=0.2536\right)$. Unadjusted DI scores were statistically associated with LCQ scores such that one unit of decrease in LCQ was associated with an increase in DI scores by 0.89 points $(\mathrm{p}=0.022)$.

\section{Laryngeal abnormalities: structural and functional}

Laryngeal functional abnormalities were categorised based upon the findings of abnormal levels of hyperfunction (anteroposterior, mediolateral or sphincteric compression i.e. simultaneous anteroposterior and mediolateral compression of vocal folds, aryepiglottic folds and ventricular folds) of the larynx at rest, during phonation or during breathing tasks. Functional abnormalities were documented in the majority of patients (44 out of 60) (figure 3) although paradoxical vocal fold motion (PVFM) was only documented in six out of 60 patients. Structural abnormalities were noted in nearly half of the patients with the majority of these being erythema and oedema (figure 3). Neurological vocal fold abnormalities were indicated in nine out of 60 (sluggish or immobile vocal folds $(n=4)$ and vocal tremor $(n=5)$ ). Only five patients had normal laryngeal appearance and function and 24 out of 60 patients exhibited overlapping structural and functional abnormalities. The occurrence of neurologic or structural abnormalities (seen in one-fifth of patients in our study) did not influence the treatment for cough.

\section{Treatment}

Besides specific treatments for GORD, rhinosinusitis and CVA, treatment recommendations for cough included behavioural speech therapy (BST) and management of comorbid obstructive sleep apnoea (OSA). BST was recommended for 56 out of 60 patients for treatment of their cough, and any other upper airway or voice complaints (figure 1). 34 out of 56 patients completed their BST while OSA management was completed in $43 \%$ with 22 new diagnoses of OSA rendered. Combinations of different therapies included BST, continuous positive airway pressure therapy (CPAP) for OSA, and management of GORD, CVA, 


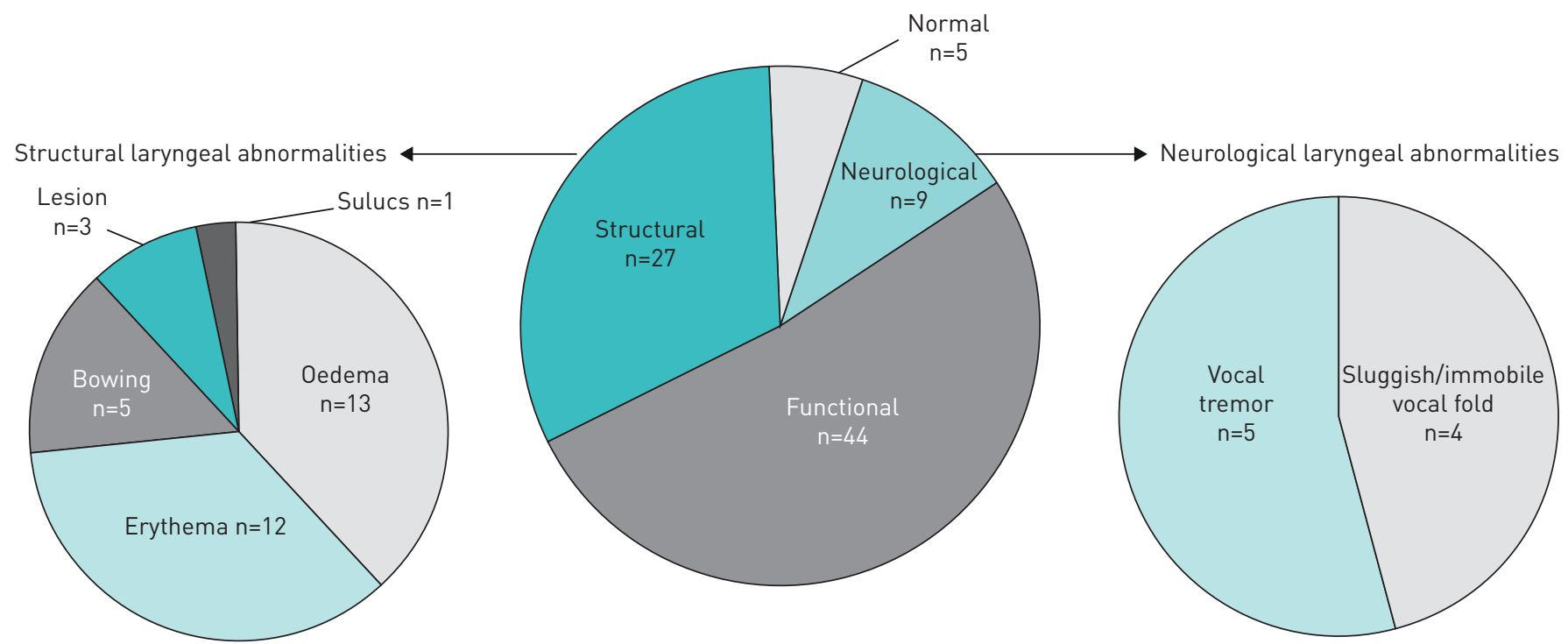

FIGURE 3 Nasoendoscopy with stroboscopy findings.

rhinosinusitis with improvement in cough noted in $34(85.0 \%)$ out of 40 patients that adhered to recommended therapies (figure 1).

\section{Discussion}

This observational study in patients with UCC and RCC determined that a high proportion of those with cough hypersensitivity (i.e. allotussia and/or hypertussia) exhibited signs or symptoms of laryngeal dysfunction. This study was unique for its interdisciplinary approach that combined the empiric clinical approach based upon the 2006 chronic cough guidelines with a comprehensive voice and airway evaluation. While an interdisciplinary approach to chronic cough has the potential for lower costs and healthcare utilisation during assessment [15], there are no studies reporting clinical outcomes associated with such a combined team-based approach. The team-based collaboration between a pulmonologist and SLP specialising in voice and airway populations pools complimentary skills in the evaluation and management of cough. For physicians dealing with chronic cough, the assessment of the voice and upper airway by an SLP and subsequent BST has the potential to lead to faster resolution of chronic cough.

Cough is a vital protective reflex preventing aspiration and the abnormal triggering of cough with activities such as eating, talking, changes in position, etc., is indicative of a sensitised cough reflex or cough hypersensitivity [16]. Cough hypersensitivity syndrome is defined as "a condition characterised by cough triggered by low levels of thermal, mechanical, or chemical exposure" [5]. Using this definition, we utilised the symptoms of allotussia and hypertussia as indicative of cough hypersensitivity and this was demonstrable in all our patients with RCC/UCC. Cough hypersensitivity can also be assessed objectively by measuring sensitivity to inhaled capsaicin given that capsaicin sensitivity is abnormal in patients with chronic cough irrespective of phenotype (UCC, GORD, CVA, rhinosinusitis) and improves with cough resolution [17-19]. However, the use of inhalational capsaicin challenge to assess cough hypersensitivity has wide diagnostic cut-offs and is not widely available. Capsaicin activates the "nociceptor" cough pathway by binding to transient receptor potential cation channel subfamily V member 1 (TRPV1) airway receptors [17]. Recent insights into mechanistic heterogeneity of cough point to the possibility of different endotypes of chronic cough [20] in which TRPV1 activation may not be a consistent abnormality. The persistence of cough in studies of novel TRPV1 receptor blockers highlights the need to recognise cough hypersensitivity beyond abnormal capsaicin sensitivity [20]. All UCC/RCC patients in this study reported one or more cough triggers with multiple triggers occurring in $75 \%$ of patients. The most common trigger for cough in UCC/RCC patients in this study was phonation (i.e. talking and laughing) as was seen in a previous study [6]. Therefore, given the hallmark finding of abnormal cough triggering in this and other studies of UCC/RCC of coughing to multiple stimuli $[6,21-28]$ (table 4) the history of allotussia and hypertussia can be considered a valuable clinical correlate for cough hypersensitivity.

Besides allotussia and hypertussia, there are other phenotypic attributes of cough hypersensitivity that are common across studies of UCC/RCC (table 4) [6,21-28]. Complaints most commonly seen with cough hypersensitivity include irritation in the throat or chest, throat clearing, dysphonia/hoarseness, upper 
TABLE 3 Laryngeal abnormalities in patients with chronic cough

\begin{tabular}{|c|c|c|c|c|c|c|}
\hline & Overall & \multicolumn{3}{|c|}{ Age-distribution } & \multicolumn{2}{|c|}{ Sex-distribution } \\
\hline Patients n & 60 & 9 & 33 & 18 & 16 & 44 \\
\hline Globus & $13(22)$ & 3 & 6 & 4 & 4 & 9 \\
\hline Tickle & $24(40)$ & 5 & 15 & 4 & 8 & 16 \\
\hline Irritation & $14(23)$ & 3 & 6 & 5 & 4 & 10 \\
\hline Mucus & $4(6)$ & 0 & 1 & 3 & 2 & 2 \\
\hline \multicolumn{7}{|l|}{ Throat clearing } \\
\hline Present & $27(45)$ & 3 & 16 & 8 & 8 & 19 \\
\hline Absent & $6(10)$ & 1 & 3 & 2 & 1 & 5 \\
\hline Not specified & $27(45)$ & 5 & 14 & 8 & 7 & 20 \\
\hline $\begin{array}{l}\text { Voice change } \\
\text { Voice Handicap Index }\end{array}$ & $32(53)$ & 4 & 16 & 12 & 7 & 25 \\
\hline Mean $\pm S D$ & $14.12 \pm 8.04$ & $20.56 \pm 18.13$ & $13.71 \pm 8.0$ & $11.31 \pm 7.3$ & $15.57 \pm 8.3$ & $13.64 \pm 7.9$ \\
\hline $\mathrm{n}$ & 56 & 9 & 31 & 17 & 14 & 42 \\
\hline
\end{tabular}

airway dyspnoea, and globus, symptoms that may indicate a significant contribution from laryngeal structures toward cough hypersensitivity [29]. Amongst these sensations, the urge to cough or somatic sensations that precede the occurrence of cough have received the most attention [30]. In most studies evaluating this symptom, these sensations are localised to the neck and ascribed by clinicians as "laryngeal paresthesias" or laryngeal sensations $[6,22,26,28]$. These laryngeal paresthesias are often present without any evident cough stimulus in patients with UCC/RCC [25]. 95\% of our UCC/RCC patients reported symptoms consistent with laryngeal paresthesias compatible with the high prevalence noted in other studies (table 4). In addition to laryngeal paresthesias, other signs or symptoms of laryngeal dysfunction included frequent throat clearing, voice abnormalities and dyspnoea, and observation of functional abnormalities during nasoendoscopy such as paradoxical vocal fold motion (PVFM) or muscle-tension dysphonia (MTD) (table 4).

Cough hypersensitivity in RCC/UCC is attributed to neuropathic changes in cough pathways within the central and peripheral limbs of cough reflex pathways. Both peripheral sensitisation and alteration in the modulating influences of central descending pathways are implicated in the causation of cough [20, 31]. Spatial and functional separation of peripheral cough afferents into chemosensory proximal airway neurons projecting to jugular vagal ganglia versus distal mechanosensitive neurons projecting to nodose vagal ganglia offer a possible mechanistic explanation for the diversity seen in the cough reflex pathway. However, much remains to be understood in terms of the neuro-structural or neuro-functional abnormalities underlying chronic cough [31]. Despite this lack of information of the spatial localisation of pathways driving cough hypersensitivity, there is increasing clinical recognition of the role of the larynx and surrounding structures in chronic cough.

The cough reflex involves the coordinated action of a number of different muscles of the chest and airway with the larynx playing a key role in the compression and expiratory phases of cough [32]. The rich innervation of the larynx enables response to tactile, chemical, and mechanical stimuli, either with cough or forceful vocal fold adduction (expiratory reflex) [33]. Laryngeal dysfunction manifesting as cough can be triggered by viral infection and perpetuated by further trauma due to throat clearing and coughing [5, 34]. Terms to describe such laryngeal dysfunction driving cough include "laryngeal hypersensitivity" and "laryngeal hyperresponsiveness" in the context of abnormal respiratory sensation [23] and/or abnormal vocal fold adduction during inspiration [27]. Whether laryngeal hypersensitivity is the only clinical correlate of cough hypersensitivity or whether other symptoms such as chest irritation represent different expressions of cough hypersensitivity is unclear [29]. 
TABLE 4 Studies of UCC/RCC with abnormalities of cough hypersensitivity and laryngeal findings

\begin{tabular}{|c|c|c|c|c|c|c|c|}
\hline $\begin{array}{l}\text { First } \\
\text { author } \\
\text { [ref.] }\end{array}$ & $\begin{array}{l}\text { Subjects } \\
\text { evaluated and } \\
\text { number } \\
\text { studied }\end{array}$ & $\begin{array}{l}\text { Abnormal cough } \\
\text { triggers In RCC/ } \\
\text { UCC }\end{array}$ & $\begin{array}{l}\text { Laryngeal } \\
\text { paresthesia }\end{array}$ & $\begin{array}{l}\text { Throat clearing } \\
\text { in UCC/RCC }\end{array}$ & $\begin{array}{l}\text { Voice abnormalities } \\
\text { and upper airway } \\
\text { dyspnoea in UCC/ } \\
\text { RCC }\end{array}$ & $\begin{array}{l}\text { Laryngeal abnormalities on } \\
\text { endoscopy }\end{array}$ & Other findings \\
\hline $\begin{array}{l}\text { VerTigan } \\
{[6]}\end{array}$ & $\begin{array}{l}111 \text { chronic } \\
\text { cough patients } \\
\text { (55 out of } 111 \\
\text { with PVFM } \\
\text { also) }\end{array}$ & $\begin{array}{l}\text { Average of } 8 \\
\text { triggers noted } \\
\text { for each } \\
\text { participant }\end{array}$ & $\begin{array}{l}41 \% \text { reported } \\
\text { warning } \\
\text { sensations with } \\
\text { most identifying } \\
\text { throat as the site } \\
\text { of trigger }\end{array}$ & $\begin{array}{l}\text { Noted but } \\
\text { percentage of } \\
\text { patients with } \\
\text { this symptom } \\
\text { not specified }\end{array}$ & $\begin{array}{l}\text { Abnormal voice and } \\
\text { dyspnoea scores in } \\
\text { chronic cough and } \\
\text { cough plus PVFM } \\
\text { patients }\end{array}$ & $\begin{array}{l}55 \text { chronic cough with PVFM } \\
\text { included in analysis }\end{array}$ & $\begin{array}{l}\text { Talking, cigarette smoke, cold air and } \\
\text { irritability in throat identified as } \\
\text { most frequent triggers. }\end{array}$ \\
\hline RYAN [21] & $\begin{array}{l}24 \text { subjects with } \\
\text { chronic } \\
\text { persistent } \\
\text { cough }\end{array}$ & Not reported & Not reported & Not reported & Not reported & $14 / 24$ noted with PVFM & $\begin{array}{l}\text { Abnormal extrathoracic airway } \\
\text { hyper-reponsiveness using } \\
\text { hypertonic saline in cough+PVFM } \\
\text { group }\end{array}$ \\
\hline $\begin{array}{l}\text { VERTIGAN } \\
\text { [22] }\end{array}$ & 53 RCC patients & $\begin{array}{l}100 \% \text { with one or } \\
\text { more cough } \\
\text { triggers }\end{array}$ & Seen in $94 \%$ & Not reported & Not reported & $\begin{array}{l}\text { Shortness of breath reported as a } \\
\text { cough trigger }\end{array}$ & $\begin{array}{l}\text { Categorised tussive and non-tussive } \\
\text { triggers to capture hypertussia and } \\
\text { allotussia }\end{array}$ \\
\hline $\begin{array}{l}\text { Bucca } \\
\text { [23] }\end{array}$ & 61 UCC & Not reported & Not reported & Not reported & Not reported & $\begin{array}{l}66 \% \text { of UCC patients had abnormal } \\
\text { LHR }\end{array}$ & $\begin{array}{l}\text { LHR seen not only in UCC but also in } \\
\text { GORD (62) asthma (41), } \\
\text { rhinosinusitis (208) }\end{array}$ \\
\hline RYAN [24] & 62 patients & $\begin{array}{l}50 \% \text { with laryngeal } \\
\text { hypersensitivity }\end{array}$ & $\begin{array}{l}63 \% \text { with central } \\
\text { reflex } \\
\text { sensitisation }\end{array}$ & Not reported & $\begin{array}{l}76 \% \text { with voice } \\
\text { changes }\end{array}$ & Not reported & $\begin{array}{l}\text { This was a placebo-controlled study of } \\
\text { gabapentin in chronic cough that } \\
\text { showed higher cough improvement } \\
\text { in those with central sensitisation. }\end{array}$ \\
\hline $\begin{array}{l}\text { VeRTIGAN } \\
\text { [25] }\end{array}$ & $33 \mathrm{RCC}$ & Not reported & $\begin{array}{l}\text { RCC patients had } \\
\text { worse laryngeal } \\
\text { paresthesia } \\
\text { scores compared } \\
\text { to controls }\end{array}$ & Not reported & $\begin{array}{l}\text { Worse VHI scores and } \\
\text { DSI as compared to } \\
\text { controls }\end{array}$ & Not reported & $\begin{array}{l}57 \% \text { of RCC had abnormal fall in } \\
\text { forced inspiratory flow }\left(\mathrm{FIF}_{50}\right) \\
\text { following hypertonic saline and } \\
\text { worse compared to control groups }\end{array}$ \\
\hline $\begin{array}{l}\text { HILTON } \\
\text { [26] }\end{array}$ & $\begin{array}{l}100 \text { consecutive } \\
\text { chronic cough } \\
\text { patients }\end{array}$ & $\begin{array}{l}79 \% \text { with } \\
\text { hypertussia } 72 \% \\
\text { with allotussia }\end{array}$ & $\begin{array}{l}75 \% \text { with neck } \\
\text { sensations }\end{array}$ & $\begin{array}{l}\sim 50 \% \text { with throat } \\
\text { clearing }\end{array}$ & Not reported & Not reported & $\begin{array}{l}\text { Correlation between urge-to-cough } \\
\text { sensation intensity and total LCQ } \\
\text { score. }\end{array}$ \\
\hline $\begin{array}{c}\text { VeRTIGAN } \\
\text { [27] }\end{array}$ & $\begin{array}{l}20 \text { patients with } \\
\text { RCC }\end{array}$ & Not reported & $\begin{array}{l}\text { Abnormal LHQ with } \\
\text { correlation with } \\
\text { cough frequency }\end{array}$ & Not reported & $\begin{array}{l}\text { Abnormal mean VHI } \\
\text { values in RCC group } \\
\text { compared to } \\
\text { controls }\end{array}$ & $\begin{array}{l}\text { Laryngeal motor dysfunction with } \\
\text { breathing in } 47 \% \text { RCC }(67 \% \text { with } \\
\text { odour challenge). Mediolateral } \\
\text { constriction of false vocal cords in } \\
45 \% \text { with incomplete or abnormal } \\
\text { vocal cord closure in } 75 \% \text { of RCC } \\
\text { group. }\end{array}$ & $\begin{array}{l}\text { Specialised voice testing and timed } \\
\text { swallow test different in RCC group } \\
\text { as compared with controls. } 69 \% \text { with } \\
\text { of } 27 \text { out of } 69 \text { patients that had } \\
\text { abnormal cough had PVFM }\end{array}$ \\
\hline Won [28] & $\begin{array}{l}62 \text { patients with } \\
\text { RCC }\end{array}$ & $\begin{array}{l}100 \% \text { of patients } \\
\text { with two or more } \\
\text { cough triggers }\end{array}$ & $\begin{array}{l}100 \% \text { of patients } \\
\text { with at least one } \\
\text { abnormal } \\
\text { sensation }\end{array}$ & Not reported & Not reported & Not assessed & $\begin{array}{l}\text { Correlations between LCQ and number } \\
\text { of laryngeal sensations, number of } \\
\text { cough triggers, } \mathrm{CHQ} \text { score }\end{array}$ \\
\hline $\begin{array}{r}\text { Current } \\
\text { study }\end{array}$ & $\begin{array}{l}60 \text { patients RCC/ } \\
\text { UCC }\end{array}$ & $\begin{array}{l}100 \% \text { with one or } \\
\text { more cough } \\
\text { triggers }\end{array}$ & Seen in $97 \%$ & $\begin{array}{l}\text { Seen in } 45 \% \text { of } \\
\text { patients }\end{array}$ & $\begin{array}{l}\text { VHI abnormal in } 43 \% \\
\text { and DI in } 75 \% \text { of } \\
\text { patients }\end{array}$ & $\begin{array}{l}\text { Functional laryngeal abnormalities } \\
\text { in } 88 \% \text { patients }\end{array}$ & $\begin{array}{l}\text { Correlations between LCQ and VHI and } \\
\text { DI noted }\end{array}$ \\
\hline
\end{tabular}


The role of laryngeal dysfunction in RCC is poorly appreciated despite reports of a wide spectrum of laryngeal abnormalities in patients with RCC (table 4). Conversely, a higher prevalence of cough is noted in patients with PVFM, MTD, and vocal cord dysfunction (VCD) $[6,22,27]$. Despite categorisation of patients into those with predominant dyspnoea (VCD), voice (MTD) and cough problems, the considerable overlap in abnormalities indicates the laryngeal airway as a major source for these syndromes $[25,27]$. Additionally, correlations between abnormalities of laryngeal and cough indices such as the LCQ highlight the potential for the vagal laryngeal afferents as the salient neuropathic substrate of cough hypersensitivity $[27,28]$. In our study, the relationship between DI and VHI with LCQ was significant and indicated that the occurrence of cough due to somatic stimuli that affect the larynx such as talking, eating, changes in position, deep breathing with position can track with upper airway dyspnoea and voice problems. However correlation does not infer causality. A recent study by VERTIGAN et al. [27] that systematically assessed patients with RCC, MTD and VCD demonstrated both a relationship between the laryngeal hypersensitivity questionnaire (LHQ) score and cough frequency along with similar impairments in voice scores and laryngoscopic abnormalities. While PVFM was only noted in a small number of patients in our study due to inconsistent use of provocation techniques, a significant prevalence of PVFM in RCC has been reported in other studies [21,27]. Another recent study on 416 chronic cough and 62 RCC patients demonstrated significant correlations between LCQ and VAS to the number of positive laryngeal sensations, number of cough triggers and cough hypersensitivity as assessed by the cough hypersensitivity questionnaire [28].

The improvement of cough with BST further supports a role for "laryngeal hypersensitivity" in driving chronic cough. In our study, it was unclear whether laryngeal hypersensitivity was an independent phenomenon or related to GORD for which $75 \%$ of patients received anti-acid therapy. Therapy for GORD is recommended in chronic cough patients that are symptomatic for GORD [35] and despite elimination of the symptoms of GORD in a significant proportion of our patients, their cough tended to persist especially in those with features of cough hypersensitivity and laryngeal abnormalities. Even though this study did not purport to assess efficacy of a particular management approach to cough, we saw improvements in cough with BST, therapy for OSA with CPAP, or the combination of both for those with GORD, rhinosinusitis and CVA. OSA, a condition characterised by recurrent trauma to the upper airway during sleep, is associated with both chronic cough [36] and laryngeal abnormalities [37, 38]. A recent longitudinal assessment showed preservation of sensory palatal thresholds after 5 years of CPAP therapy as compared to worsening in untreated snorers [39]. Further research is necessary to unravel the association between GORD and OSA and laryngeal hypersensitivity and the role of BST along other therapies typically recommended.

The 2006 ACCP cough guidelines paved the way for systematic analysis and treatment of chronic cough [2]. An anatomic diagnostic protocol as outlined in the cough guidelines identifies disease aetiologies for cough from almost all regions with cough afferents. However, disorders of the larynx were omitted from the list of aetiologies for chronic cough. Instead, laryngeal symptoms associated with chronic cough were attributed to GORD [40] and upper airway cough syndrome [41] in chronic cough patients.

\section{Limitations}

Despite being a retrospective, single-centre study, this report offers important insights into the value of an interdisciplinary assessment for UCC/RCC that includes systematic laryngeal evaluation. Currently, there is no agreement on the protocol for laryngeal evaluation for chronic cough due to the lack of consensus regarding functional laryngeal anomalies and laryngeal hypersensitivity [42]. The operator dependency of results, sporadic nature of laryngeal complaints, lack of validated cut-offs for laryngeal closure and lack of understanding of how mechanical or other stimuli uncover laryngeal dysfunction can further confound the diagnosis of laryngeal hypersensitivity [42]. To address reliability issues inherent with clinical interpretation of laryngeal structure and function in nasoendoscopy recordings, an SLP independently documented impressions blind to the original finding for purposes of this study. However, future studies need to systematically evaluate nasoendoscopy findings across multiple clinic sites to further examine this study's finding of laryngeal functional abnormalities in UCC/RCC. In this study, validated questionnaires to assess complaints of hypertussia, allotussia and abnormal laryngeal sensation were not used. The VHI and DI were used to assess voice and upper airway dyspnoea respectively although the validated laryngeal hypersensitivity questionnaire (LHQ) was not used to assess laryngeal hypersensitivity [43]. One of the goals of this study was to determine whether laryngeal dysfunction as assessed by SLPs during their routine clinical evaluation could elucidate the potential contribution of laryngeal hypersensitivity to chronic cough. This aspect is important given that other practitioners need to be able evaluate for laryngeal dysfunction based on symptom assessment (as is done for other aetiologies of cough) and refer patients with laryngeal dysfunction for appropriate management early on in disease course before prolonged and frequently ineffective empiric therapeutic trials are done. 


\section{Conclusion}

This report highlights the prevalence of a constellation of symptoms typifying laryngeal dysfunction and cough hypersensitivity with a call to designate laryngeal hypersensitivity as a specific phenotype of cough. The larynx has been termed as the "pinnacle of cough" given the integration of motor processes at this location that are required for the execution of the cough reflex [41]. Although further work is required to validate the proposed criteria for laryngeal hypersensitivity, its high prevalence [44] and response to BST [13] makes it a necessary to evaluate for laryngeal hypersensitivity during the management of the patient with chronic cough. The use of targeted questions to identify both laryngeal dysfunction and cough hypersensitivity can delineate the syndrome of laryngeal hypersensitivity and facilitate development of therapies directed at the underlying neuropathic basis of cough.

Acknowledgments: Authors thank the speech language pathologists at the Voice Disorders Center (Tiffany Lyon, Julia Ellerston and Elizabeth Hary) and Marshall Smith for the multidisciplinary evaluations of patients studied in this cough clinic. We also thank all the referring providers within the Pulmonary, ENT, Internal Medicine, Family Practice and Allergy clinics within and outside the University of Utah Health Care system.

Data availability: Individual participant data after deidentification that underlie the reports results detailed in the articles (text, tables, figures).

Conflict of interest: K.M. Sundar attended one advisory board for Merck in August 2020 (\$1175.00), was a site principal investigator (PI) for a study on iVAPS validation of an expiratory positive airway pressure algorithm funded by Resmed Inc., received nonfinancial support for a study on sham continuous positive airway pressure in chronic cough from Respironics Inc., and was a site PI for VOLCANO-2 funded by NeRRe Therapeutics Inc., outside the submitted work. A.C. Stark has nothing to disclose. N. Hu has nothing to disclose. J. Barkmeier-Kraemer has nothing to disclose.

\section{References}

1 Chung KF, Pavord ID. Chronic cough 1 prevalence, pathogenesis and causes of chronic cough. Lancet 2008; 371: 1364-1374.

2 Pratter MR, Brightling CE, Boulet LP, et al. An empiric integrative approach to the management of cough: ACCP evidence-based clinical practice guidelines. Chest 2006; 129: 1suppl, 222S-231S.

3 Gibson PG, Vertigan AE. Management of chronic refractory cough. BMJ 2015; 351: h5590.

4 Morice $\mathrm{AH}$. The cough hypersensitivity syndrome: a novel paradigm for understanding cough. Lung 2010; 188: Suppl. 1, S87-S90.

5 Morice AH, Millqvist E, Belvisi MG, et al. Expert opinion on the cough hypersensitivity syndrome in respiratory medicine. Eur Respir J 2014; 44: 1132.

6 Vertigan A, Theodoros D, Gibson P, et al. Voice and upper airway symptoms in people with chronic cough and paradoxical vocal fold movement. J Voice 2007; 21: 361-383.

7 von Elm E, Altman DG, Egger M, et al. Strengthening the reporting of observational studies in epidemiology (STROBE): guidelines for reporting of observational studies. BMJ 2007; 335: 806-808.

8 Birring SS, Prudon B, Carr AJ, et al. Development of a symptom specific health status measure for patients with chronic cough: Leicester Cough Questionnaire (LCQ). Thorax 2003; 58: 339-343.

9 Jacobson BH, Johnson A, Grywalski C, et al. The voice handicap index (VHI) development and validation. Am J Speech Lang Pathol 1997; 6: 66-70.

10 Gartner-Schmidt JL, Shembel AC, Zullo TG, et al. Development and validation of the Dyspnea Index (DI): a severity index for upper airway-related dyspnea. J Voice 2014; 28: 775-782.

11 Patel RR, Awan SN, Barkmeier-Kraemer J, et al. Recommended protocols for instrumental assessment of voice: American Speech-Language-Hearing Association expert panel to develop a protocol for instrumental assessment of vocal function. Am J Speech Lang Pathol 2018; 27: 887-905.

12 McGarvey L, McKeagney P, Polley L, et al. Are there clinical features of a sensitized cough reflex? Pulm Pharmacol Ther 2011; 2009; 22: 59-64.

13 Chamberlain Mitchell SA, Garrod R, Clark L, et al. Physiotherapy, and speech language therapy intervention for patients with refractory chronic cough: a multicenter randomized control trial. Thorax 2017; 72: 129-136.

14 Epstein LJ, Kristo D, Strollo PJ Jr, et al. Clinical Guideline for the Evaluation, Management and Long-term Care of Obstructive Sleep Apnea in Adults. J Clin Sleep Med 2009; 15: 263-276.

15 Patton CM, Lim KG, Ramlow LW, et al. Increasing efficiency in evaluation of chronic cough: a multidisciplinary, collaborative approach. Q Manage Health Care 2015; 24: 177-182.

16 Chung KF, Widdicombe JG. Cough: Setting the scene. In: Chung R, Widdicombe R, eds. Handbook of Experimental Pharmacology. Pharmacology and Therapeutics of Cough. Berlin Heidelberg, Springer-Verlag, 2009; 187: pp. 1-21.

17 Birring SS. The search for hypersensitivity in chronic cough. Eur Respir J 2017; 49: 1700082.

18 Song W-J, Morice AH. Cough hypersensitivity syndrome: a few more steps forward. Allergy Asthma Immunol Res 2017; 9: 394-402.

19 O'Connell F, Thomas VE, Pride NB, et al. Capsaicin cough sensitivity decreases with successful treatment of chronic cough. Am J Respir Crit Care Med 1994; 150: 374-380.

20 Mazzone SB, Chung KF, McGarvey L. The heterogeneity of chronic cough: a case for endotypes of cough hypersensitivity. Lancet Respir Med 2018; 6: 636-646.

21 Ryan NM, Gibson PG. Characterization of laryngeal dysfunction in chronic persistent cough. Laryngoscope 2009; 119: 640-645.

22 Vertigan AE, Gibson PG. Chronic refractory cough as a sensory neuropathy: evidence from a reinterpretation of cough triggers. J Voice 2011; 5: 596-601. 
Bucca C, Bugiani M, Culla B, et al. Chronic cough and irritable larynx. J Allergy Clin Immunol 2011; 127: 412-420.

24 Ryan NM, Birring SS, Gibson PG. Gabapentin for refractory chronic cough: a randomized, double-blind, placebo-controlled trial. Lancet 2012; 380: 1583-1589.

25 Vertigan AE, Bone SL, Gibson PG. Laryngeal sensory dysfunction in laryngeal hypersensitivity syndrome. Respirology 2013; 18: 943-956.

26 Hilton E, Marsden P, Thurston A, et al. Clinical features of the urge-to-cough sensation in patients with chronic cough. Respir Med 2015; 109: 701-707.

27 Vertigan AE, Kapela SM, Kearney EK, et al. Laryngeal hypersensitivity in cough hypersensitivity syndrome: a cross-sectional observational study. J Allergy Clin Immunol Pract 2018; 6: 2087-2095.

28 Won H-K, Kang S-Y, Kang Y, et al. Cough-related laryngeal sensations and triggers in adults with chronic cough: Symptom profile and impact. Allergy Asthma Immunol Res 2019; 11: 622-631.

29 Chung KF. Approach to chronic cough: the neuropathic basis for cough hypersensitivity syndrome. I Thoracic Dis 2014; 6: Suppl. 7, S699-S707.

30 Davenport PW. Urge-to-cough: What can it teach us about cough? Lung 2008; 186: Suppl. 1, S107-S111.

31 Mazzone SB, Undem BJ. Vagal afferent innervation of the airways in health and disease. Physiol Rev 2016; 96: 975-910.

32 Polverino M, Polverino F, Fasolino M, et al. Anatomy and neuro-pathophysiology of the cough reflex arc Multidiscip Respir Med 2012; 7: 5.

33 Ludlow C. Laryngeal reflexes: physiology, technique and clinical use. J Clin Neurophysiol 2015; 32: 284-293.

34 Irwin RS, Ownbey R, Cagle PT, et al. Interpreting the histopathology of chronic cough: a prospective, controlled, comparative study. Chest 2006; 130: 362-370.

35 Kahrilas PJ, Altman KW, Chang AB, et al. Chronic cough due to gastroesophageal reflux in adults CHEST guideline and expert panel report. CHEST 2016; 150: 1341-1360.

36 Sundar KM, Willis AM, Smith S, et al. A randomized, controlled, pilot study of CPAP for patients with chronic cough and obstructive sleep apnea. Lung 2020; 198: 449-457.

37 Roy N, Merrill RM, Pierce J, et al. Evidence of possible irritable larynx syndrome in obstructive sleep apnea - an epidemiologic approach. J Voice 2020; in press: https://doi.org/10.1016/j.jvoice.2020.02.006.

38 Nguyen AT, Jobin V, Payne R, et al. Laryngeal and velopharyngeal sensory impairement in obstructive sleep apnea. Sleep 2019; 28: 575-593.

39 Svanborg E, Ulander M, Broström A, et al. Palatal sensory function worsens in untreated snorers but not in CPAP-treated patients with sleep apnea, indicating vibration-induced nervous lesions. CHEST 2020; 157 1296-1303.

40 Phua SY, McGarvey LP, Ngu MC, et al. Patients with gastroesophageal reflux disease and cough have impaired laryngopharyngeal mechanosensitivity. Thorax 2005; 60: 488-491.

41 Altman KW, Lane AP, Irwin RS. Otolaryngology aspects of chronic cough. J Allergy Clin Immunol 2019; 7: $1750-1755$.

42 Famokunwa B, Walsted ES, Hull JH. Assessing laryngeal function and hypersensitivity. Pulm Pharmacol Ther 2019; 56: 108-115.

43 Vertigan AE, Bone SL, Gibson PG. Development and validation of the Newcastle laryngeal hypersensitivity questionnaire. Cough 2014; $10: 1$.

44 Roy N, Stemple J, Merrill RM, et al. Epidemiology of voice disorders in the elderly: preliminary findings. Laryngoscope 2007; 117: 628-633. 